\title{
Desarrollo de productos sanitarios de protección personal y de uso en laboratorio de análisis con prototipado rápido
}

\author{
Ma. Fernanda Rodríguez, ${ }^{1,2}$; Marcos D. Actis ${ }^{1}$; Alejandro J. Patanella ${ }^{1}$ \\ ${ }^{1}$ Centro Tecnológico Aeroespacial - Facultad de ingeniería - Universidad Nacional de La Plata; ${ }^{2}$ \\ fernanda.rodriguez@alu.ing.unlp.edu.ar
}

Resumen. La pandemia de COVID-19 que nos encontramos atravesando se ha presentado como un desafío para la humanidad. El desconocimiento de la enfermedad provocada por el virus SARSCoV-2 y el resultante colapso de los sistemas de salud de cada país comenzaron a espejar las decisiones políticas de subestimar al virus (o de privilegiar la frenética inercia del sistema que creíamos era lo único que conocíamos). La anticipación política argentina de enfrentar la pandemia con una cuarentena (distanciamiento social obligatorio) dejó en claro que la prevención excedía la demanda del sector de salud pero permitió reformular los sistemas de acción, así la sociedad, las instituciones y entidades de ciencia y tecnología, como el Centro Tecnológico Aeroespacial (CTA), encontraron un punto de confluencia para resolver las diferentes demandas a través de redes de procesos colaborativos, como los casos que describiremos de insumos de laboratorio, para análisis de tests e hisopados de COVID-19, y de elementos de bioseguridad, que responden al Protocolo de Equipamiento de Protección Personal recomendado por la Organización Mundial de la Salud/ elevado por el Ministerio de Salud de la Nación, para trabajadores esenciales. Los desarrollos fueron abordados bajo la perspectiva de diseño abierto, gestando un FabLab, dentro del CTA, de tecnología de fabricación por métodos aditivos (FDM).

Palabras clave: diseño código abierto; FAB-LAB; prototipado rápido; COVID-19; protocolo EPP; test hisopados; sistema; globalidad; desarrollo local

Recibido: 02/10/2020 Aceptado: 08/10/2020

DOI: https://doi.org/10.24215/26838559e018 
Innovación y Desarrollo Tecnológico y Social (2020) 2 (2): 83-117- Número especial COVID-19

\title{
Development of medical devices for personal protection and for use in analysis laboratories with rapid prototyping
}

\begin{abstract}
The COVID-19 pandemic that we are experiencing has been presented as a challenge for humanity. The ignorance of the disease caused by the SARS-COV-2 virus and the resulting collapse of the health systems of each country began to mirror political decisions to underestimate the virus (or to privilege the inertia of the system that we believed was the only thing that we knew). Argentina's political anticipation of facing the pandemic with a quarantine (mandatory social distancing) made it clear that prevention exceeded the demand of the health sector but allowed the reformulation of action systems, as well as society, institutions and science and technology entities, such as the Aerospace Technology Center (CTA), they found a point of convergence to solve the different demands through collaborative process networks, such as the cases that we will describe of laboratory supplies, for analysis of COVID-19 tests and of bio-security elements, which respond to the Protocol for Personal Protective Equipment recommended by the World Health Organization / raised by the Ministry of Health of the Nation, for essential workers. The developments were approached from the perspective of open design, creating a FabLab, within the CTA, of manufacturing technology by additive methods (FDM).
\end{abstract}

Keywords: open source design; FAB-LAB; rapid prototyping; COVID-19; EPP protocol; swab test; system; globality; local development

\section{Novedad u originalidad local en el conocimiento}

El principal desafío supuso repensar el sistema global productivo, para productos de Protocolos de Protección Personal (EPP) ${ }^{1}$ e insumos de laboratorio que se vieron

\footnotetext{
${ }^{1}$ Protocolo de Protección Personal (EPP) - Productos y métodos de utilización de los mismos para protegerse de riesgos laborales dentro de actividades nomencladas. Dictaminados por la OIT (Organización Internacional del Trabajo) y la OMS (Organización Mundial de la Salud), contemplados en Argentina bajo la Ley № 19.587, aplicación provista por la Resolución $N^{\circ}$ $896 / 99$ y la No 299/2011.
} 
altamente requeridos y el distanciamiento social obligatorio ralentizaba las vías de comercialización. Se requería un nuevo sistema productivo de asistencia en el marco de la cuarentena, así las herramientas, procesos y formatos de fabricación digital se transformaron en el eje de acción.

El voluntariado (profesionales e impresores 3D autoconvocados -Makers ${ }^{2}$ ) sumado al redireccionamiento de actividades y recursos de las instituciones, que presentaban la misma inquietud solidaria, confluyeron en una red de Diseño Colaborativo Abierto $^{3}$, donde los usuarios finales (personal sanitario y de laboratorio) se transformaron en participes activos del proceso de diseño.

De pronto, la misma globalidad que había esparcido al virus SarsCoV-2, se presentaba como la vía de acción para contrarrestarlo, los diseños de código abierto comenzaban a desparramarse por los países afectados a través de la web, permitiendo anticiparnos al sistema de las pruebas y errores que estos objetos

\footnotetext{
${ }^{2}$ Movimiento de "hacedores", desprendido de la corriente DIY (do it yourself), donde las herramientas productivas se resumen en maquinaria asequible, de orden técnico hobbista o semi-industrial, que les permite a las personas (sin ser dueñas de una industria) desde sus hogares acceder al prototipado rápido mediante fabricación digital, es decir modelados CAD derivando en aplicación CNC, impresión 3D, corte láser, etc.

${ }^{3}$ Diseño abierto, conocido también como Open Design, diseñando en clave Open Sourse código abierto, paradigma que propone la liberación de la propiedad intelectual de una obra para que ésta puede ser cedida para su evolución (reproducir y/o modificada abiertamente), no implica libre de autoría, sino de acceso libre.
} 
presentaban pudiendo incorporar al personal sanitario y laboratorial dentro de la retroalimentación de requerimientos y usabilidad específicos a su contexto.

\section{Grado de relevancia}

El eje principal fue la gestión de la cadena productiva dentro del sistema de cuarentena. Con el objetivo central de generar Diseño Abierto de incidencia global, de rápida diseminación que movilice a su escalabilidad por producciones individuales en sumatoria, pudiendo replicarse en cualquier región. Para ello, la perspectiva colaborativa entre sociedad civil e instituciones fue clave en la estrategia.

Para productos EPP la articulación se gestó entre la Escuela de Aeromodelismo La Plata (EALP), el Laboratorio de Software Libre para Arte y Diseño (SLAD-FA-UNLP), el Centro Tecnológico Aeroespacial (CTA-UNLP) y la Comunidad Makers La Plata, con retroalimentación del personal sanitario. Esta estrategia de vinculación en medio del sistema de cuarentena, que afectaba principalmente a los impresores voluntarios, se definió ejecutando el convenio marco entre la EALP y la UNLP para aumentar recursos y organizar la logística, es decir recolección de las impresiones y entrega de material para producción entre participantes, infraestructura para el acopio, clasificación, desinfección y entrega al personal sanitario. En paralelo con la organización, el objetivo diseño fue la adecuación ergonómica e inclusiva de los 
usuarios (contemplando el amplio espectro de percentiles antropométricos) y la revisión de cumplimiento de normas ISO, UNE, CEE, para bio-seguridad.

Para el desarrollo de insumos de laboratorio se respondió con diseño retroactivo entre personal del Laboratorio VacSal IBBM-FCE UNLP y el CTA. Para este caso la articulación entre las maquinarias disponibles del CTA y del GEMA (Grupo de Ensayos Mecánicos Aplicados), conformando un FabLab (granja de impresoras 3D por método aditivo - FDM) orientado a la pandemia.

El objetivo de rediseño de soportes para análisis de muestras en función de los recientes desarrollos de kit de testeos donde la configuración metodológica del proceso de análisis en pooles ${ }^{4}$ requería redimensionar la escala de uso.

\section{Grado de pertinencia}

El concepto de diseño abierto global y respuesta de aplicación local es esencial para comprender la ejecución productiva en contexto de cuarentena y aislamiento preventivo, las herramientas digitales de la mano de profesionales (autoconvocados y pertenecientes a las distintas UIDETs pertenecientes al CTA) hicieron posible la cocreación de productos reversionados, basados en modelos de libre acceso, y

\footnotetext{
${ }^{4}$ Sistema de análisis por muestreo agrupado, estrategia desarrollada conjuntamente por el equipo del laboratorio VacSal-UNLP (dirigido la Dra. Hozbor) y el equipo de FCEN-UBA (Dres Etchenique y Pecci). El sistema permite utilizar los kits de detección del virus que emplea el Anlis-Malbrán mediante RT-PCR, abordando muestreo masivo reduciendo costos y tiempo.
} 
adecuados a los requisitos específicos de bio-seguridad. Permitiendo que cada impresor 3D voluntario pudiera, desde su casa, contribuir con la producción local, evento al cual se suman los FabLabs de las UIDETs.

Para todos los casos de diseño abierto la conjugación de las herramientas de producción y los requerimientos específicos de uso para mitigar los efectos del COVID-19 se definieron entre inputs de diseño (metodología centrada en el usuario y bioseguridad) y restricciones del FabLab (cantidad de impresoras 3D FDMque definen la granja, dimensiones de las mesas de impresión, y la organización de producción).

El trabajo fue organizado desde la virtualidad, a través de equipos con roles específicos (de diseño, de asistencia técnica para impresoras 3D, de gestión, logística, compras, entre otras), para los productos EPP, partiendo desde repositorios open source, rediseñando en función del contexto, para los insumos de laboratorio generando diseño abierto desde su base, y para ambos casos, empleando materia prima nacional (filamento principalmente PLA y flejes de acetato, PETt u otros).

Finalmente, la gestión, desde la comitiva Makers + EALP como la gestión institucional UNLP + CTA, actuó como canalizador de las producciones individuales, conjugándolas en un sistema de logística de integración. 


\section{Grado de demanda}

La declaración de emergencia sanitaria (DECNU-2020-260-APN-PTE) estableció el distanciamiento social obligatorio siguiendo las recomendaciones de la OMS. La medida de cuarentena se yuxtapuso con la elevación de protocolo interinstitucional de los centros de salud, donde el Protocolo de Equipo Personal de Protección (EPP) ascendió a categoría AlII ${ }^{5}$, derivado de las medidas llevadas adelante por el Ministerio de Salud (RESOL-2020-568-APN-MS). Aquello elevó la demanda del equipo completo de nivel facial para todos los niveles de atención médica, equipo compuesto por antiparras selladas, tapa bocas Niosh 95 (o similares tricapa) y pantallas faciales. Quedando el equipo integral (mono, cofias, cubre-zapatos, guantes) para las áreas de mayor contaminación ambiental o de intervención directa de pacientes. El rápido crecimiento de la curva de contagio expuso la urgencia de acceder a las protecciones adecuadas para las cuales los hospitales y centros de salud no estaban preparados. Allí surge responder a la demanda de pantallas faciales.

De la misma manera, obligó a la reconfiguración de sistema de análisis de muestras para detección de COVID-19 dentro de los laboratorios. El VacSal-FCE-UNLP, en

\footnotetext{
${ }^{5}$ Categorizaciones de prevención, tanto metodológica como EPP correspondiente a cada etapa de la atención de salud. Las recomendaciones Inter-Institucionales fueron dadas por el Ministerio de Salud, distribuida por sus asociaciones derivadas (SADI / SATI /ADECI /INE). Elevadas a máximo nivel, Alll, para accionar preventivo ante el COVID-19.
} 
conjunto con FCEN UBA (en coordinación con el Ministerio de Salud de la Provincia de Buenos Aires) desarrollaron la estrategia de análisis en pooles, para enfrentar entre 200 y 450 casos diarios, volumen que excedía el material de soporte y clasificación que debió ser rediseñado.

Actualmente se han entregado más de 10mil pantallas faciales (en trabajo conjunto con Makers LP) en la ciudad de La Plata y zonas aledañas. Nos encontramos desde el CTA acercando material a las ciudades del interior de la provincia que han comenzado con brotes al iniciar la Fase 3 y 4 (Saladillo, Tapalque, otros).

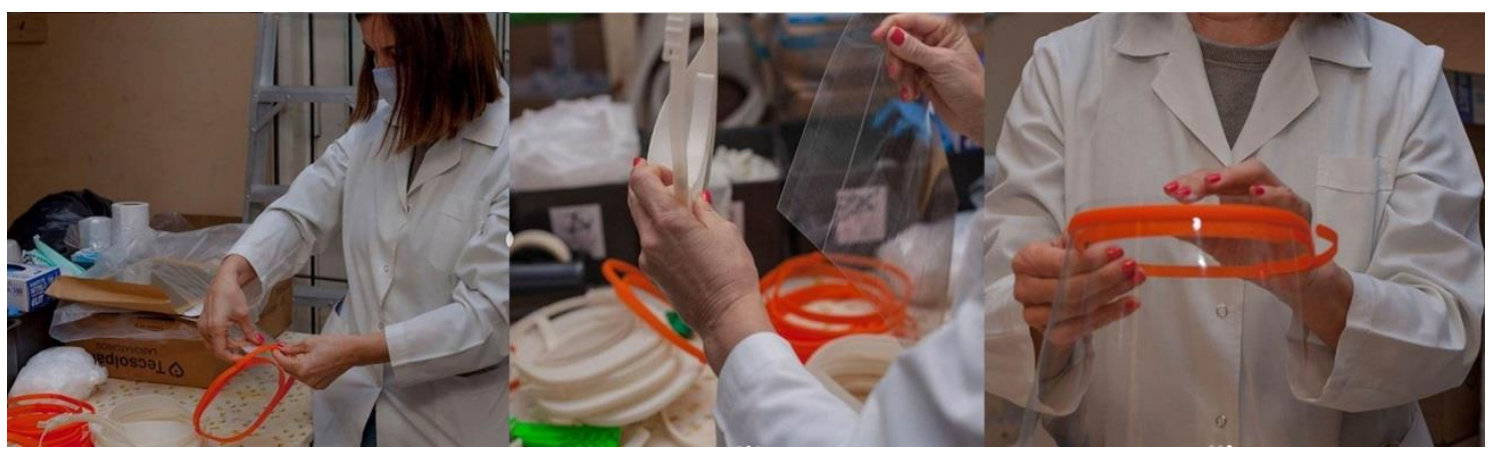

Figura 1. Armado de pantallas faciales en Tapalqué.

Figure 1. Face shield assembly in Tapalqué.

Notas en las que aparece el desarrollo colaborativo del modelo de uso sanitario:

- https://www.argentina.gob.ar/ciencia/prioridadcoronavirus/iniciativas-encurso

- https://www.eldia.com/nota/2020-4-13-2-46-11-platenses-hacen-mascaras3d-para-hospitales-de-la-region-informacion-general 
- https://investiga.unlp.edu.ar/cienciaenaccion/la-facultad-de-artes-se-suma-

a-la-produccion-de-mascaras-faciales-17841

- https://unlp.edu.ar/coronavirus/con-impresoras-3d-la-unlp-fabricamascaras-protectoras-para-personal-de-la-salud-17681

- https://www.0221.com.ar/nota/2020-3-27-21-41-0-la-unlp-imprimemáscaras-para-proteger-a-los-trabajadores-de-la-salud-del-coronavirus Algunos de los trabajos para equipamiento de laboratorio:

- https://www.instagram.com/vacsal_ibbm/

\section{Desarrollo del producto}

A partir de las mencionadas transformaciones de sistemas productivos colaborativos para la pandemia, describiremos los productos sobre los cuales se ha trabajado desde el FabLab generado en el CTA. Poniendo a disposición maquinaria FDM, impresoras 3D, pertenecientes al CTA y al GEMA (Grupo de ensayos Mecánicos Aplicados), y LaCLyFA (Laboratorio de Capa Límite y Fluidodinámica Ambiental) UIDET confluyente del CTA. Así se adecuaron 6 impresoras, cinco de 20×20×20cm y uno de $40 \times 40 \times 50 \mathrm{~cm}$ de volumen de trabajo.

\section{Pantallas faciales}

Las pantallas faciales se transformaron dentro de la lista de los EPP a fabricar aquellos más solicitados por su limitada presencia en el mercado nacional, 
resultando costosos y siendo en su mayoría específicos de producción fabril, metalurgia, otros.

La iniciativa comienza sobre archivos Open Source, la pantalla facial que inicialmente se selecciona y se imprime deriva de la Mascara Ferrovial "SAS 1" diseñada en España (por Sicnova y dispuesta por Sistema Sanitario Público de Andalucía) disponibles en un repositorio web (cuarta imagen de la Figura / modelo A de la Tabla 1), permitieron comenzar con la producción inmediatamente, para darle marcha al sistema de provisión de recursos materiales, logística de reparto de materia prima y recolección de viseras impresas, para luego acopiarlas en el predio del comedor de la Facultad de Ingeniería y terminar con el ensamblaje, desinfección y entrega. Las primeras modificaciones las gestionaron dentro del sub-equipo de diseño coordinado por el SLAD integrado por diseñadores e impresores (autonvocados, de la EALP, del CTA y del SLAD), para desarrollar piezas accesorias, además de ajustes de parámetros y asistencia para coordinar las más de 120 impresoras articuladas desde la organización Makers LP (cada una con su software, su nivel de tolerancias y sus particularidades funcionales).

Parte de las modificaciones contaron con el aporte de los médicos del Policlínico San Martín de La Plata quienes hicieron retroactiva su participación como testers de las protecciones. De esta manera comenzó un proceso colaborativo de diseño y producción de equipamiento de protección para la emergencia sanitaria. 
EI CTA participó articulando dentro del equipo las adecuaciones normativas pertinentes al Protocolo EPP, siguiendo las normas UNE-EN 1666-2002, ANSI/ISEA Z87.1-2015, UE 86/686/CEE, ISO equivalentes, y revisiones ergonómicas (solicitadas por resoluciones del Ministerio de Trabajo y Ministerio de Salud). Así dentro de la conformación de un equipo multidisciplinar surgieron diferentes propuestas de pantallas faciales que responden con mayor inclusividad diferentes perfiles de rostro a la vez que permiten utilizar debajo de la misma, antiparras selladas y tapabocas formato copa o pico de pato las cuales tienen mayor volumen. De éstas derivaron en un modelo de ventilación indirecta para evitar que se empañe la lámina transparente a la vez que cubre la parte superior entre la pantalla y la frente evitando las salpicaduras de gotas, y por otro lado se dejaron para impresiones extra, modelos de ventilación directa que permiten ser utilizados en áreas de menor riesgo como espacios ventilados, uso comercial, uso administrativo (tal es el caso del personal no docente parte del voluntariado de la UNLP).

Es necesario remarcar que, por el nivel de propagación del virus y la urgencia de entregar equipamiento de protección, la etapa que se correspondería con ensayos físicos que puedan homologar los productos se delegó, en correspondencia con la génesis de Diseño Abierto, al trabajo de campo, es decir, muestras de pruebas realizadas por los impresores, y así mismo dentro del FabLab gestado en el CTA, y luego una segunda etapa de pruebas y testeos de uso por parte del personal médico. 
Proceso Colaborativo en Etapas: (orden cronológico)

\section{Etapa 1}

Algunos de los modelos testeados en la primer y segunda semana de cuarentena (declarada el 20 de marzo), extraídos del repositorio Portal COVID-19:

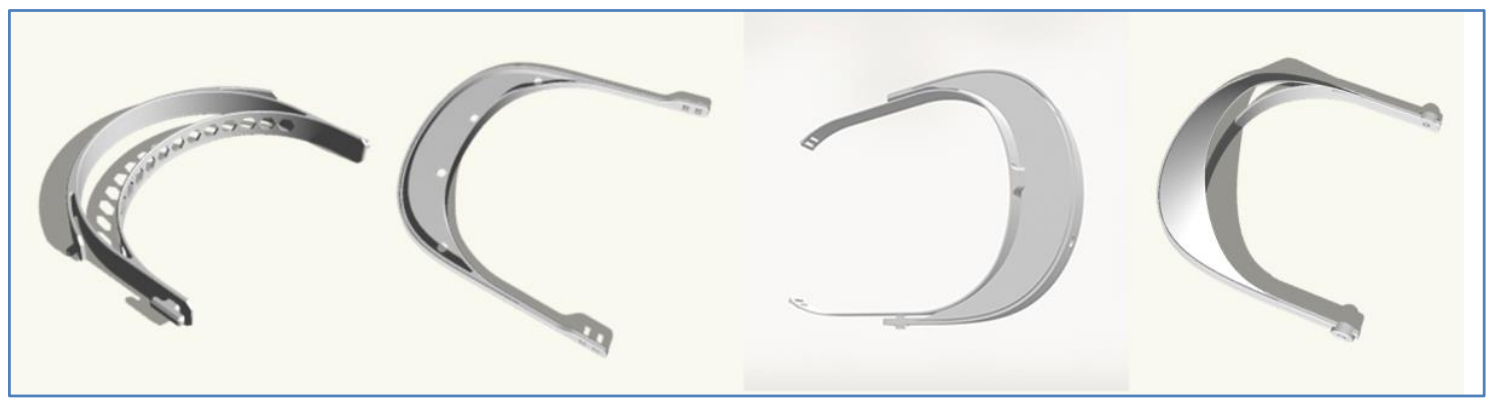

Figura 2. Modelos de diseño abiertos propuestos en PortalCOVID-19.

Figure 2. PortaICOVID-19 open design models.

Se descarta el primer modelo por ser abierto y poseer complejidad en el vínculo móvil para impresiones rápidas y de baja calidad. Se descartan el segundo y tercer modelo por la rigidez que presentaron en las pruebas para adaptarse a distintas curvas de frentes y la incomodidad de las patillas del tercer modelo que rozan en el cuero cabelludo de ciertos contornos mayores de cráneo, dado el ángulo cerrado de los mismos. Restando la cuarta propuesta que fue seleccionada por flexibilidad a la vez que poseía un plano inclinado para salpicaduras y micro gotas. 
Innovación y Desarrollo Tecnológico y Social (2020) 2 (2): 83-117- Número especial COVID-19

Tabla 1. Generación de diseños abiertos basado en el modelo Sicnova (España) > resultados de DI Particulares+SLAD+CTA+EALP (asociados dentro de MakersLP).

Table 1. Open Design creation based on Sicnova Spain model > Designers+SLAD+CTA+EALP (Makers LP asociation) result models.

\begin{tabular}{|c|c|c|c|c|c|c|}
\hline Modelo & Imagen General & Ventilación tipo & $\begin{array}{c}\text { Ajustes de } \\
\text { cabeza tipo/func. }\end{array}$ & $\begin{array}{c}\text { Plan B ajuste } \\
\text { de cabeza }\end{array}$ & $\begin{array}{l}\text { Traba de } \\
\text { pantalla }\end{array}$ & Pantalla tipo \\
\hline $\begin{array}{c}\text { A } \\
\text { Sicnova }\end{array}$ & & $\begin{array}{l}\text { Mixta. } \\
\text { Directa por el tamaño } \\
\text { de apertura/ indirecta } \\
\text { porque la visera que } \\
\text { cubre de aerosoles de } \\
\text { gotas mayores. }\end{array}$ & $\begin{array}{l}\text { 3er elemento/ } \\
\text { elástico, cinta, } \\
\text { otros (depende } \\
\text { del usuario). }\end{array}$ & Único. & No. & Recambia-ble. \\
\hline $\begin{array}{c}\text { B } \\
\begin{array}{c}\text { Makers LP + } \\
\text { SLAD }\end{array}\end{array}$ & & $\begin{array}{l}\text { Mixta. } \\
\text { Ídem prop. A. }\end{array}$ & $\begin{array}{l}\text { 3er elemento/ } \\
\text { traba impresión } \\
\text { 3D. }\end{array}$ & $\begin{array}{r}\text { Si. } \\
\text { Orificios }\end{array}$ & $\begin{array}{l}\text { 3er elemento } \\
\text { Impreso 3D. }\end{array}$ & Recambia-ble. \\
\hline
\end{tabular}




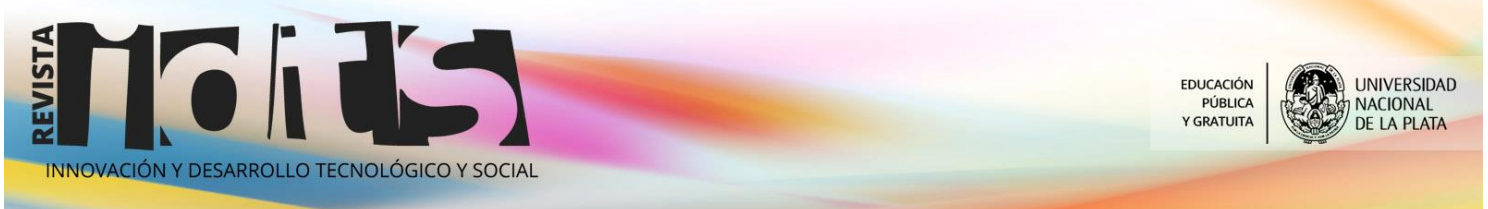

Innovación y Desarrollo Tecnológico y Social (2020) 2 (2): 83-117- Número especial COVID-19

\begin{tabular}{|c|c|c|c|c|c|c|}
\hline Modelo & Imagen General & Ventilación tipo & $\begin{array}{c}\text { Ajustes de } \\
\text { cabeza tipo/func. }\end{array}$ & $\begin{array}{c}\text { Plan B ajuste } \\
\text { de cabeza }\end{array}$ & $\begin{array}{c}\text { Traba de } \\
\text { pantalla }\end{array}$ & Pantalla tipo \\
\hline $\begin{array}{c}\text { C } \\
\text { Makers LP + } \\
\text { EALP + CTA }\end{array}$ & & $\begin{array}{l}\text { Directa. } \\
\text { Para uso comercial o } \\
\text { espacios ventilados/ no } \\
\text { apta uso de espacios } \\
\text { contaminados. }\end{array}$ & $\begin{array}{l}\text { Integrado } \\
\text { /impresión 3D. }\end{array}$ & $\begin{array}{r}\text { Si. } \\
\text { Ganchos }\end{array}$ & No. & Recambia-ble. \\
\hline $\begin{array}{c}\text { D } \\
\text { Makers LP + } \\
\text { SLAD + CTA }\end{array}$ & $\xi$ & $\begin{array}{l}\text { Mixta. } \\
\text { *Reduce la visera que } \\
\text { ofrece la ventilación. }\end{array}$ & $\begin{array}{l}\text { Integrado/ } \\
\text { impresión 3D. }\end{array}$ & $\begin{array}{c}\text { Si. } \\
\text { Ganchos }\end{array}$ & No. & Recambia-ble. \\
\hline
\end{tabular}




\section{Etapa 2}

El modelo $B$, enlistado en la Tabla 1, muestra las dos primeras modificaciones que son la corrección de tolerancia de impresión para la ranura de encastre para las láminas/pantalla transparente del modelo A, dejando la posibilidad abierta según con el proveedor con quien se pudiese articular, considerando que el rollo de acetato, PET u otro material pudiera ser de 150, 200 o 250 micras de espesor. Al igual que el agregado de un borde inferior de contención de la lámina (no cumple como mentonera de protección), fue pensada para mantener la curvatura de la misma ante el movimiento de la cabeza o roce contra el propio pecho del usuario. Este modelo presentaba la complejidad de tres piezas (modelo gestionado para su impresión por Makers LP desde la segunda hasta la 6 semana de la cuarentena).

\section{Etapa 3:}

Se observa junto con el personal médico que testeó las pantallas, durante la etapa 2, las siguientes revisiones de diseño referente a la usabilidad inmediata:

- El sistema de ajuste era endeble;

- Que el soporte inferior de la filmina pese a ser un elemento extra es requerido por el mismo personal para mantener la curva de la filmina, decidimos conservarla;

- La visera si bien es flexible generaba algunas reacciones de roce con la piel después de largas jornadas de uso; 
- La profundidad de la visera A no contemplaba la profundidad de narices de percentil 95\% ni tampoco el uso de barbijos tipo copa o pico de pato, por ello la proximidad hacía que se empañe la pantalla;

- La traba de filmina/pantalla transparente a varios usuarios se les perdía o rompía en procesos de traslado.

Aquí comienzan dos procesos simultáneos de diseño, por un lado, propuestas para resolver problemas de efectivización del sistema de impresión y prototipado rápido, generándose propuestas que acaban conformando el Modelo C. Y por el otro lado comienzan las revisiones de diseño y adecuaciones ergonómicas que confluyen en el Modelo D, que se traducen en una respuesta de enfoque centrada en el usuario, el usuario como protagonista activo.

El modelo C, surge como diseño alternativo a la impresión de piezas individualizadas del modelo B (visera + traba para lámina transparente + soporte inferior), pudiendo hacer una impresión integral, éste modelo por su economía de materiales, su velocidad de impresión y su simpleza fue adecuado en espesores por el CTA en un trabajo conjunto e incorporado a la línea de impresión del FabLab en paralelo al modelo B, siendo el modelo B destinado a personal sanitario (por su cualidad de ventilación indirecta) y el modelo $\mathrm{C}$ destinado a personal de uso en áreas abiertas o de bajo riesgo en bio-seguridad. Este modelo responde a una tipología de uso diferente a solucionar, reemplaza otro nicho que permite mayor economía material/tiempo. Así mismo no es apto para uso médico, ni sectores contaminados 
con potencialidad de aerosoles, por lo tanto, no se compara con los modelos A-B o

el D. Fue requerido para el personal de la UNLP, y también destinado a administrativos (sin riesgo de contaminación viral ambiental) del área salud de los Municipios de Tapalqué y de Saladillo.

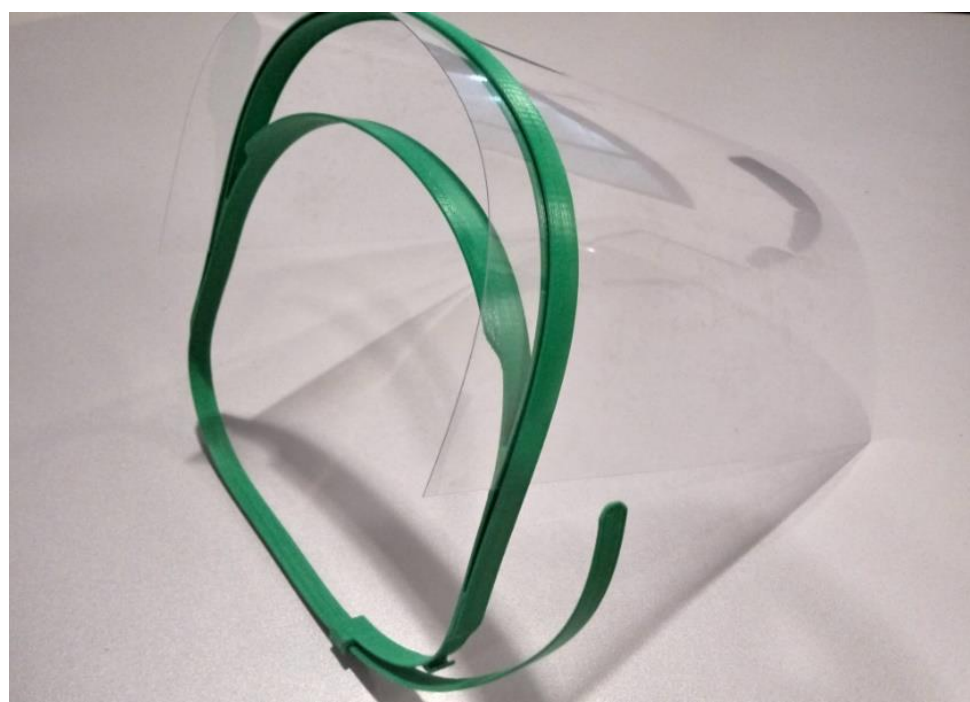

Figura 3. Pantalla facial de ventilación directa modelo C (destinada a la UNLP, verde institucional).

Figure 3. Direct ventilation face shield (produced to UNLP, institutional green).

La calidad de ajuste de tolerancias del modelo $C$ depende del conocimiento de la máquina y de una mínima calidad de la impresora (en cuanto a mantenimiento y ajustes, en caso de no contar con ello se puede prever el agregado de la lámina de traba originado en el modelo B).

Dada las cualidades es el modelo madre de los diseños PFD y PFT (continuaciones del equipo de diseño) aunque éstos dos últimos no incluyen los ganchos accesorios que posee este modelo, los cuales están pensados ante la erosión de la cinta 
pasante o rotura eventual, para ser atados con una bandita elástica convencional (pudiendo cortar con una tijera las cintas plásticas y el mecanismo también si se lo deseara).

El modelo $D$, según la Tabla 1, es el resultado de una revisión normativa y ergonómica más profunda del equipo multidisciplinar (dentro de un proceso de al menos diez configuraciones de modelos que fueron presentadas entre los diseñadores participantes). Pretende corregir los errores de la mascaras de diseño abierto presentes en el mercado, muchos de los cuales a la fecha ya se estaban comercializado a elevado costo a través de plataformas de comercio digital sin ningún tipo de revisión ni garantía de bio-seguridad.

Para las revisiones del Modelo $B$, surgieron diseños integrados basados en el Modelo C, que además incorporaban el plano de protección para aerosoles, se eliminó la traba de la pantalla transparente generando relieves en la ranura de inserción de la lámina (ejerciendo presión contra la misma), propusieron un sistema flexible para el contacto con la frente del usuario, permitiendo que la pantalla se amolde a cada fisonomía.

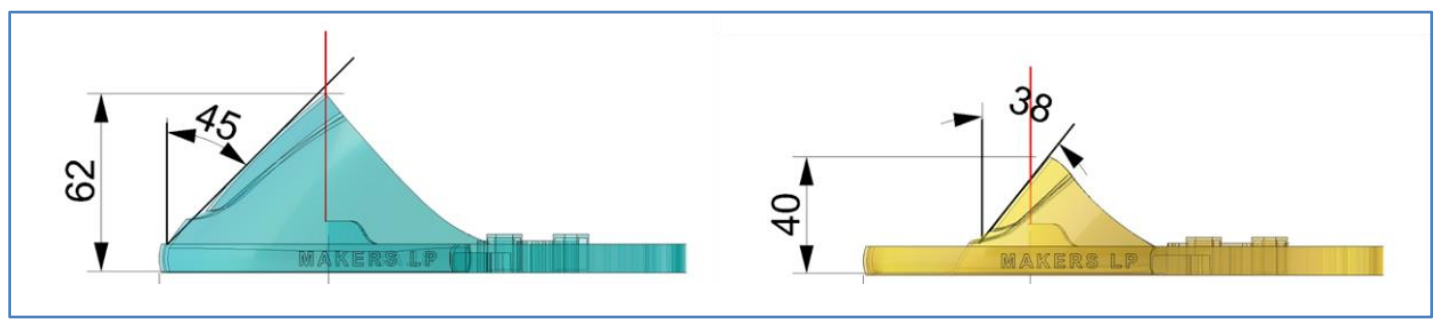

Figura 4. Comparativas de análisis de impresión del ángulo de la ventilación indirecta.

Figure 4. Comparison analysis of the printing angle of the indirect ventilation. 
En la Figura 4 se muestra la revisión final, donde el diseño de la izquierda es el resultado de las revisiones antropométricas, es decir amplía su rango de uso y de percentiles incluidos, la visera Modelo B tenía una profundidad de $51 \mathrm{~mm}$ desde el borde de la pantalla hasta el plano de apoyo con la frente, las revisiones llevan esa medida a $62 \mathrm{~mm}$, aquello que permite no solo mayores dimensiones nasales sino también, el uso de barbijo formato de copa y antiparras selladas. Con las ampliaciones dimensionales inclusivas fue necesario hacer correcciones de bioseguridad, se presentaban propuestas que requerían disminuir la apertura de la ventilación directa ante el riesgo de aerosoles, aquello que permitió llevar a la cama de impresión 35mm de base de apoyo, generando un plano de inclinación de tan sólo $38^{\circ}$, resolviendo también las dificultades técnicas de impresión.

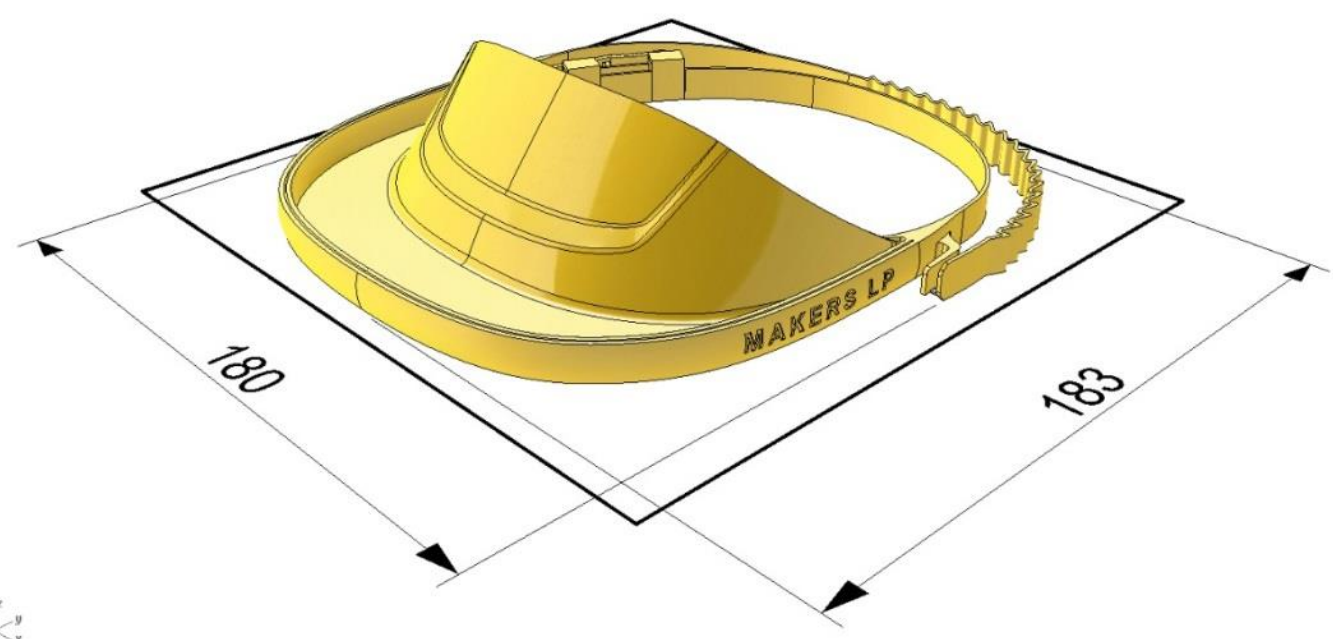

Figura 5. Modelo final de ventilación indirecta.

Figure 5. Final model of the indirect ventilation. 
Resumen de proceso de revisión normativa y ergonómica de corrección para la generación modelo final

Considerando las siguientes normas:

- ISO/IEC Guide 51:2014 - Safety aspects - Guidelines for their inclusion in standards > Antesala para hablar en terminus de prevención, seguridad y factores de riesgo.

- ISO 14971:2019 - Medical devices - Application of risk management to medical devices > Aplicación de conceptos y gestión de riesgo en concordancia o devenido de los protocolos independientes adoptados por el Ministerio de Salud de la Nación Argentina, en avance a las recomendaciones de la OMS.

- ISO 4007:2018 - Personal protective equipment - Eye and face protection Vocabulary.

- ISO 16321-1 [en revisión] - Protección ocular y facial para uso ocupacional - Parte 1: Requerimientos generales (DISF).

- ISO 19734 - Protección ocular y facial - Guía de selección, uso y mantenimiento (DIS).

- ISO 18526-1:2020 - Eye and face protection - Test methods - Part 1: Geometrical optical properties > depende del proveedor de material para pantalla facial.

- ISO 18526-2:2020 - Eye and face protection - Test methods - Part 2: Physical optical properties > estimable a nivel configuración geométrica del diseño. 
- ISO 18526-3:2020(en) - Eye and face protection - Test methods - Part 3: Physical and mechanical properties > parte de la visera: estimable/ parte de la pantalla: depende del proveedor de material para pantalla facial.

- ISO 18526-4:2020(en) - Eye and face protection - Test methods - Part 4: Headforms

- ISO/TS 16976-2:2015(en) - Respiratory protective devices - Human factors Part 2: Anthropometrics - Empleado para establecer compatibilidad entre los diferentes productos intervinientes del Kit/Conjunto EPP para COVID-19.

Las equivalencias consideradas:

- UNE-EN 168:2002 - Protección individual de los ojos. Métodos de ensayo no ópticos.

- Directiva 89/686/CEE - Comité Europeo de Normalización (CEN) y del Comité Europeo de Normalización Electrotécnica (CENELEC). - Equipos de Protección Individual (EPI) - Versión consolidad de valor documental - derogada y sustituida por el Reglamento (UE) 2016/425.

- Reglamento (UE) 2016/425 - DEL PARLAMENTO EUROPEO Y DEL CONSEJO DE LA UE - Relativo a los equipos de protección individual y por el que se deroga la Directiva 89/686/CEE del Consejo (Texto pertinente a efectos del EEE). - Se aplica:

ANEXO I - Generalidades de la categoría I de riesgos, agregando riesgo biológico; 
ANEXO II - Referente a la directiva 89/686/CEE, contemplado en la legislación Argentina.

ANEXO III - Documentación técnica.

- Recomendación (UE) 2020/403 - DE LA COMISIÓN EUROPEA - Relativa a la evaluación de la conformidad y los procedimientos de vigilancia del mercado en el contexto de la amenaza que representa el COVID-19.

Para la incorporación de la mayor cantidad de percentiles, con el fin de hacer la pantalla más inclusiva, y no restrictiva a un promedio se resolvieron el ajuste de los siguientes parámetros:

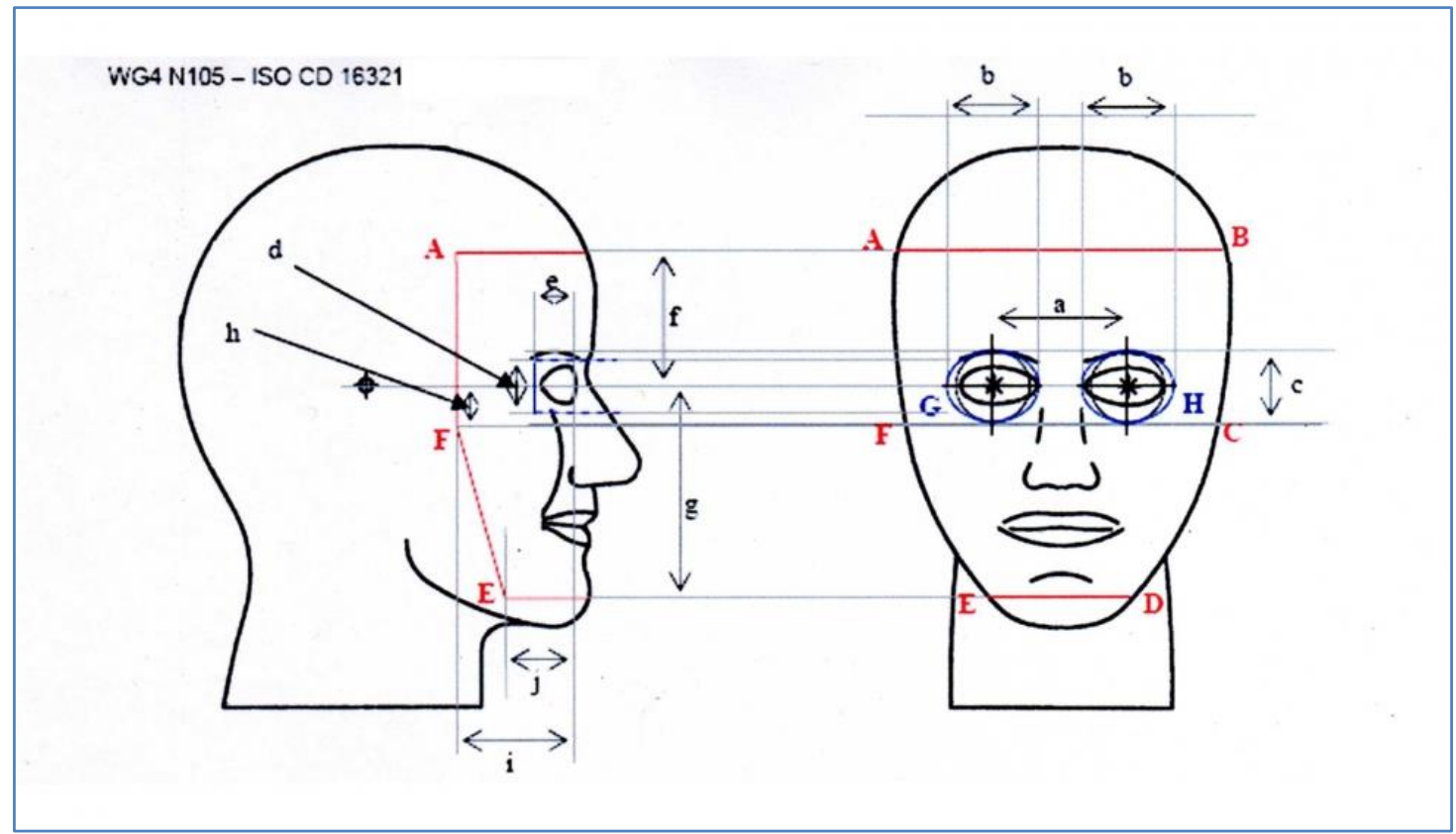

Figura 6. ISO CD 16321 - Adecuación de dimensión facial y plano visual.

Figure 6. ISO CD 16321 - Adequacy of facial dimension and visual plane. 
- Las distancias de los globos oculares $\mathrm{G}$ y H, cuyos ejes sagitales craneal-visual se separan por la distancia "a", se considera la medida de ancho máxima (percentil 95\%) que resulta estar entre 63 y $70 \mathrm{~mm}$ - medida acotada en celeste en la Figura 7.

- El ángulo de curva para la pantalla transparente resuelve una curva que persigue la rotación del ojo y campo visual de espectro circular, de $10^{\circ}$ hacia cado lado del eje visual. Medidas dentro de las que se manifiesta confort visual y de movimiento ocular. Siendo $15^{\circ}$ el máximo ángulo de confort.

- Debe recordarse que la distancia de enfoque óptimo al objeto de estudio es de 300mm, y aquí hay una pantalla transparente de por medio. Razón por la que es motivo excluyente dentro de las normas que puede poseer un tratamiento antirayas o bien que pueda ser de fácil recambio para, ante su desgaste, proteger la vista de fatiga y posibles daños laborales.

- El plano visual central, que conforma un ángulo máximo de límite visual para el percentil mayor, de $62^{\circ}$ desde el meridiano sagital del cráneo, ante la imposibilidad por emergencia de resolución del producto de ensayos ópticos, se resuelve mantenerlo prácticamente sin curvatura, a una distancia de $62 \mathrm{~mm}$ desde el apoyo de la visera hasta que la proyección visual se encuentra con la pantalla transparente.

- Así también, el apoyo flexible en la frente se desarrolla sobre la curvatura del percentil femenino más chico (5\% cuya curva de cráneo ronda los $135 \mathrm{~mm}$ ). Este 
Innovación y Desarrollo Tecnológico y Social (2020) 2 (2): 83-117- Número especial COVID-19

diseño pretende incorporar a médicas y enfermeras de percentiles no contemplados incluso por las marcas comerciales que realizan EPP homologado.

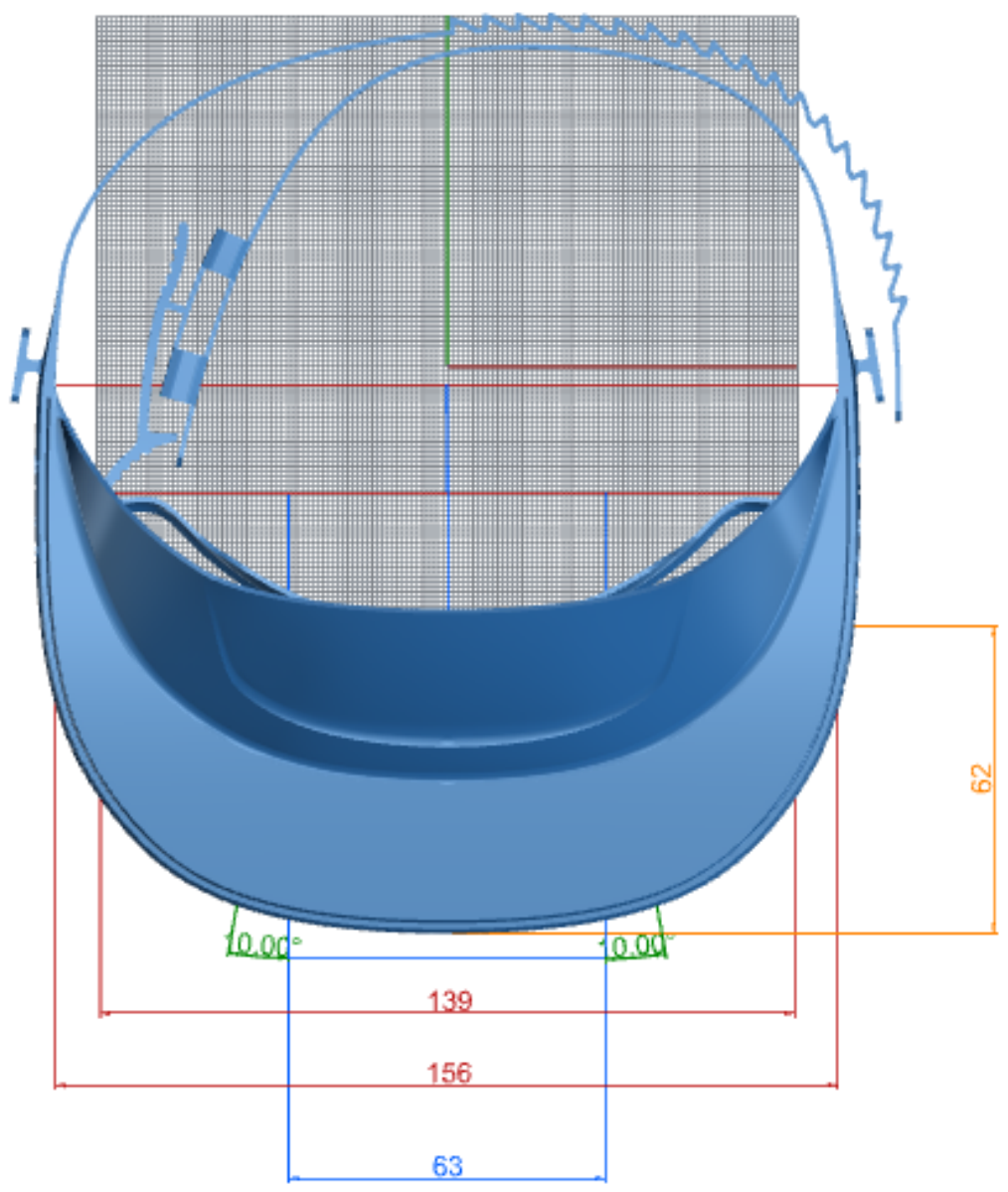

Figura 7. Resultados de correcciones ergonómicas y normativas.

Figure 7. Results of ergonomic and normative corrections.

La Tabla 2 refleja las mejoras y optimizaciones del trabajo sinérgico en equipo para el desarrollo de pantallas faciales. Mejorando desde las propiedades de impresión, 
los métodos de testeo y regulación previos a la impresión (volcándose el contenido en un grupo de asistencia técnica). Así como la mejora en la economía material, aquello que permitió al grupo de diseñadores participantes avanzar con las impresiones hasta llegar a formato de impresión tipo torre (impresión apilable para secuenciar dentro de una misma cama):

Donde el modelo $D$ si bien se obtienen dos unidades menos que el modelo $A$, resuelve todas las piezas de manera integral, ahorrando la logística y búsqueda de elásticos o zunchos.

Tabla 2. Aspectos de diseño para impresión 3D.

Table 2. 3D printing desing topics.

\begin{tabular}{cccccccc}
\hline Modelo & $\begin{array}{c}\text { Cant. } \\
\text { Piezas }\end{array}$ & $\begin{array}{c}\text { Incorpora } \\
\text { ajuste }\end{array}$ & $\begin{array}{c}\text { Plan B } \\
\text { ajuste }\end{array}$ & $\begin{array}{c}\text { ¿Requiere } \\
\text { material } \\
\text { soporte? }\end{array}$ & $\begin{array}{c}\text { Tiempo } \\
\text { impresión } \\
\mathbf{6 0 m m} / \mathbf{s e g}\end{array}$ & $\begin{array}{c}\text { Sistema } \\
\text { impre. } \\
\text { en } \\
\text { torre }\end{array}$ & $\begin{array}{c}\text { Rendi- } \\
\text { miento } \\
\mathbf{x ~ k g} .\end{array}$ \\
\hline A & 1 & No & Único & $\begin{array}{c}\text { Si, en } \\
\text { orificios. }\end{array}$ & $1.50 \mathrm{hs}$ & No & 22 \\
\hline B & 3 & $\begin{array}{c}\mathrm{Si} \\
\text { individual } \\
\text { (resorte) }\end{array}$ & $\begin{array}{c}\mathrm{Si} \\
\text { (Orificios) }\end{array}$ & $\begin{array}{c}\text { Si, en } \\
\text { orificios. }\end{array}$ & $2.40 \mathrm{hs}$ & No & 18 \\
\hline C & 1 & Integrado & $\begin{array}{c}\mathrm{Si} \\
\text { (Ganchos) }\end{array}$ & No & $0.38 \mathrm{hs}$ & $\mathrm{Si}$ & 35 \\
\hline D & 2 & Integrado & $\begin{array}{c}\mathrm{Si} \\
\text { (Ganchos) }\end{array}$ & No & $2.25 \mathrm{hs}$ & $\mathrm{No}$ & 20 \\
\hline
\end{tabular}

Considerando los siguientes parámetros de impresión fijos para todos los modelos:

- Altura de capa: 0.28mm (nozzle 0.4)

- Capas superiores: 3

- Capas inferiores: 3

- Capas laterales: 2

- Relleno: $15 \%$ 


\section{Gradillas}

El laboratorio VacSal-IBBM-Conicet recurrió al CTA, después de la divulgación de trabajo en equipo para Makers LP generando soluciones en impresión 3D para asistir en la pandemia. Aquí el problema presentado fue el pedido de rediseño de gradillas que permitan al equipo del laboratorio trabajar con la nueva estrategia de análisis por muestreo agrupado, pooles, donde el volumen de casos diarios dejaba sin soportes de trabajo al laboratorio. Para ello se trabajó conjuntamente en dos diseños:

1ro- Que reúne 100 muestras por bloque, para tubos tipo Eppendorf (de $11 \mathrm{~mm}$ de diámetro y $35 \mathrm{~mm}$ de altura), de $30 \mathrm{~mm}$ de altura, cubriendo $27 \mathrm{~mm}$ de los tubos, manteniendo una distancia de $5 \mathrm{~mm}$ entre muestra y muestra. Este diseño presentó dos revisiones, y la mejora esencial hacia el modelo final presente en la Figura 8, fue el grip y profundidad de inserción de las manos para poder movilizar las gradillas. 2do- Del cuál se muestran 2 versiones en la Figura 8, que responden a la agrupación de 35 muestras de hisopados (los modelos azules con blanco traslúcido y verde oscuro con verde claro), para tubos de kits de testeo rápido desarrollados por el Conicet. Este modelo fue ensayado en dos etapas, en la primera las asas de agarre pertenecían a la impresión del bloque medio, funcionando a la vez como encastre, cuya limitación de diseño se presentaba a la hora de transferir el diseño abierto a quienes necesitasen reproducir el mismo en camas de impresión 3D de 20×20cm, quedando limitado a las impresoras mayores (no tan habituales en el público 
general). Por ello se resuelve el agarre desde la morfología de la placa lateral, donde de las sustracciones superior e inferior (que definen las patas de apoyo) resultan de interfaz (guía visual de agarre de la gradilla). Se conforma de dos placas pasantes y una tercera placa que funciona de base y contención, siendo de mayor espesor con una concavidad receptora del tubo.

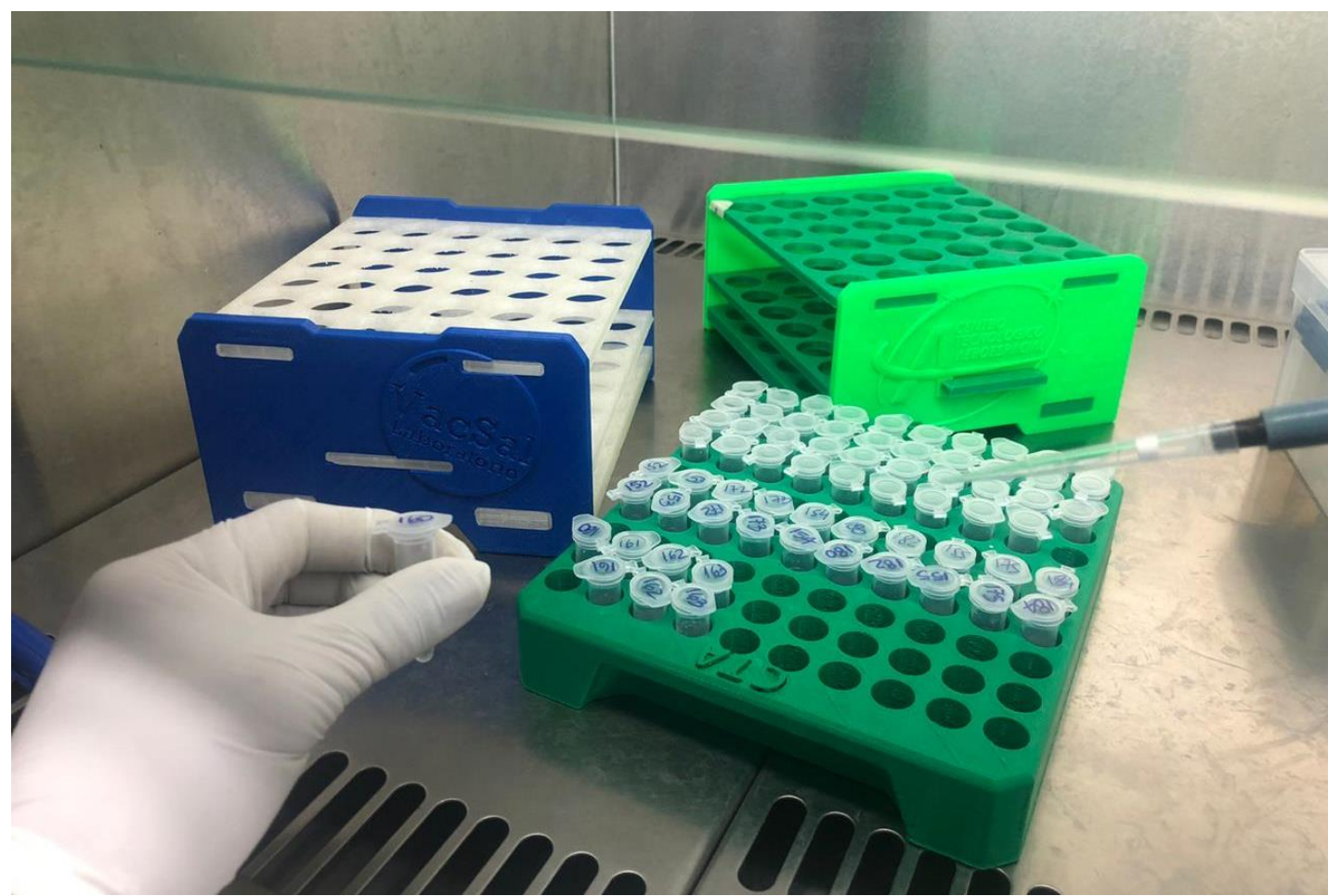

Figura 8. Gradilla en bloque de $10 \times 10$ y gradillas desarmables de $6 \times 6$.

Figure 8. Tube racks $10 \times 10$ in a single block and $6 \times 6$ in detachable configuration.

\section{Gradillas refrigeradas}

Gradillas contenidas en cajas con tapa (diferentes diseños de traba), donde se deposita un gel refrigerante debajo de la gradilla que contiene las muestras. Muchas preparaciones dentro de los laboratorios, ya sean suspensiones bacterianas, 
enzimas, reactivos o en estes caso, análisis de COVID-19, ácidos nucleicos resultan termolabiles. Pequeños cambios de temperatura pueden resultar en la degradación total o parcial. Las gradillas refrigeradas o iso freezer generan un ambiente frío y duradero que permite la manipulación por fuera del freezer y su traslado en caso de ser necesario en las mejores condiciones posibles de temperatura.

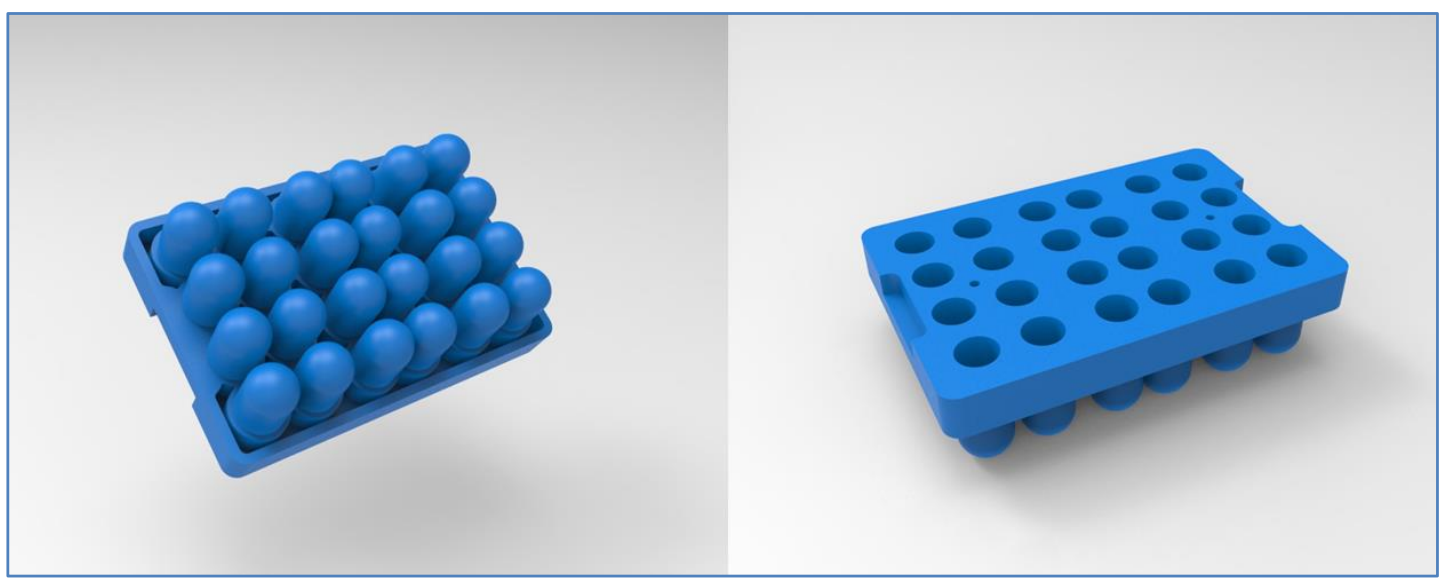

Figura 9 - Rediseño de la gradilla contenedora.

Figure 9 - Eppendorff tube rack design.

El rediseño, presente en la Figura 9, responde en principio a la escacez de insumos en el mercado, y en segundo lugar al trabajo de análisis específico con muestras para análisis de COVID-19 para tubos tipo Eppendorf (tubos de centrífuga), las gradillas disponibles para mini-freezers suelen ser en su mayoría racks abiertos (Figura 8) comaprativa de contacto diercto con el gel refrigerante. Para el caso de muestreo basado en RT-PCR se cuida a la muestra conteniendo de manera estanca al tubo, y evitando su contacto directo con el gel refrigerante. Se diseñó un modelo 
cuya pared de cobertura es de $2 \mathrm{~mm}$ y se le realizaron sustracciones para que el gel pueda llegar lo más arriba posible dentro de la gradilla (se aprecia en la Figura 9 y 10). También se le agregaron dos orificios pasante, como se ve en la cara superior del modelado (Figura 10) que sirve para dentro de la operación de montaje de la gradilla refrigerada, colocar primero la gradilla dentro de la caja contenedore y luego con una geringa inyectar el gel a través de los orificios.

El modelo rediseñado responde a las marcas que fabrican mini-freezers de las dimensiones relevadas, y en este caso el calce la gradilla es de ajuste estanco y por calce de forma (a presión) garantizando seguridad en la movilidad y traslado.

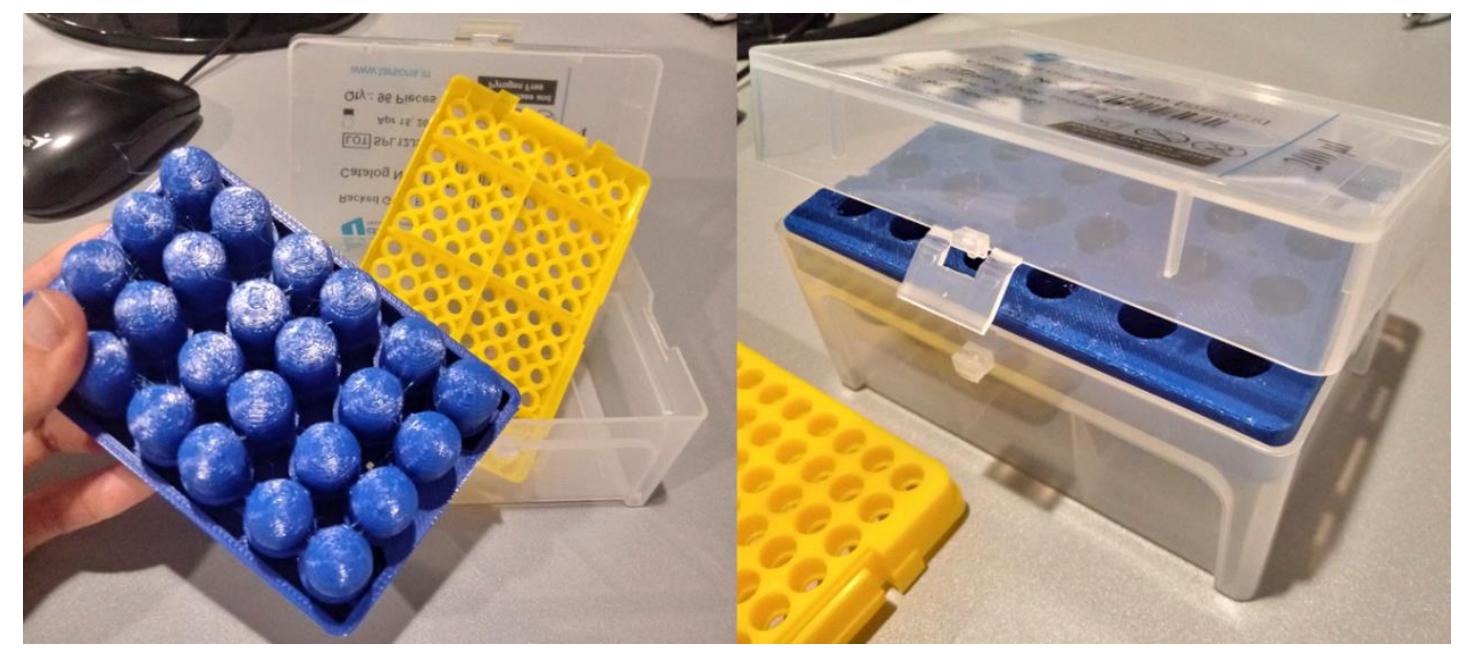

Figura 10. Actual testeo de funcionamiento y adaptación a cajas de marcas comerciales.

Figure 10. Printing testing of the first prototype. Tested to fit commercial boxes. 


\section{Soportes de tapaboca de uso hospitalario > asistente/tutor de EPP}

También fueron desarrollados las variantes de modelos dentro de la sinergia colaborativa, entre el CTA y el equipo del Hospital de niños de La Plata, iniciando con un modelado digital de código abierto, al cual se le realizaron las respectivas adecuaciones antropométricas, tanto para la dimensión de la cabeza de los niños, como para el personal de percentiles debajo del 50\%, ya que el modelo distribuido de manera global corresponde al rango 50-95\%. Entre otros agregados de diversificación del uso, la morfología ovoide vino a solventar la variación del radio craneal, a la vez que sirve para su re-posicionamiento sobre el eje sagital pudiendo en su zona libre hacer uso pasante del cabello, para sus diferentes ataduras sin que el soporte de barbijo (dentro del orden de la acción de colocación y retiro de las EPP) mueva o afecte la cofia o monoprenda de protección.

Estos modelos aún se encuentran bajo proceso de testeo en uso por el personal del Hospital de Niños de la ciudad de La Plata. 
Tabla 3. Análisis de diseño y de impresión para soportes de tapabocas EPP.

Table 3. PEP mask 3D printing and desing topics of analyze.

\begin{tabular}{|c|c|c|}
\hline Modelo 1 & Modelo 2 & Modelo 3 \\
\hline Material: PLA & Material: PLA & Material: PLA \\
\hline $\begin{array}{l}\text { Parámetros de impresión } \\
\text { - } \quad \text { Altura de capa: } 0.25 \mathrm{~mm} \\
\text { (nozzle 0.4)/0.3mm } \\
\text { (nozzle 0.6) } \\
\text { - } \quad \text { Capas superiores: } 3 \\
\text { - } \quad \text { Capas inferiores: } 3 \\
\text { - } \quad \text { Relleno: } 20 \% \\
\text { - } \quad \text { Soporte: no } \\
\text { - } \quad \text { Velocidad: } 60 \mathrm{~mm} / \mathrm{s}\end{array}$ & $\begin{array}{l}\text { Parámetros de impresión } \\
\text { - } \quad \text { Altura de capa: } 0.24 \mathrm{~mm} \\
\text { (nozzle } 0.4 \text { ) } \\
\text { - } \quad \text { Capas superiores: } 3 \\
\text { - } \quad \text { Capas inferiores: } 3 \\
\text { - } \quad \text { Capas laterales: } 2 \\
\text { - } \quad \text { Relleno: para el valor de } \\
\text { capa no requiere relleno } \\
\text { (0.24*3*3=1.44) } \\
\text { - } \quad \text { Soporte: } \text { no } \\
\text { - } \quad \text { Velocidad: } 60 \mathrm{~mm} / \mathrm{s}\end{array}$ & $\begin{array}{l}\text { Parámetros de impresión } \\
\text { - } \quad \text { Altura de capa: } 0.24 \\
\text { - } \quad \text { (nozzle } 0.4 \text { ) } \\
\text { - } \quad \text { Capas superiores: } 3 \\
\text { - } \quad \text { Capas laterales: } 2 \\
\text { - } \quad \text { Relleno: para el valor de } \\
\text { capa no requiere relleno } \\
\text { (0.24*3*3=1.44) } \\
\text { - } \quad \text { Soporte: no } \\
\text { - } \quad \text { Velocidad: } 60 \mathrm{~mm} / \mathrm{s}\end{array}$ \\
\hline $\begin{array}{l}\text { Modelo original propuesto } \\
\text { por Sicnova y 3d Novatech } \\
\text { en España. }\end{array}$ & $\begin{array}{l}\text { En este modelo se plantean } \\
3 \text { talles, también } \\
\text { diferenciados por } 10 \mathrm{~mm} \text {, la } \\
\text { proporción final se reduce a } \\
2 / 3 \text { de su modelo } \\
\text { predecesor para trabajar } \\
\text { con contornos craneales de } \\
\text { niñxs. }\end{array}$ & $\begin{array}{l}\text { Este modelo se presenta } \\
\text { como una versión } \\
\text { simplificada, que también } \\
\text { se resuelve dentro de los } \\
\text { 2/3 del ancho del modelo 1, } \\
\text { pretende solventar } \\
\text { conicidades propias de } \\
\text { formatos aguzados de } \\
\text { nucas. Su dimensión agrega } \\
\text { la posibilidad de utilizar el } \\
\text { soporte como pasante de } \\
\text { cabello largo (para cola de } \\
\text { caballo o rodete) siendo } \\
\text { funcional a percentiles } \\
\text { tanto masculinos 5-50\% } \\
\text { como femeninos 5-70\%. }\end{array}$ \\
\hline
\end{tabular}




\section{Información sobre el registro de la innovación o desarrollo}

Todos los productos generados en este contexto de pandemia han sido desarrollados bajo "código abierto", es decir que se les ha otorgado Licencia Creative Commons, adoptando las atribuciones de "bien común", libre de ser copiado, reproducido y reutilizado, con la idea fundamental de acelerar los procesos de replicabilidad y escalabilidad (local > zonal > regional).

Los equipos relevados y rediseñados se comprenden dentro de un marco de emergencia sanitaria, es decir, que posee la condición excepcional de ser un producto gratuito, para donaciones en el marco de la cuarentena, bajo licencia CC, tipología CC BY-NC-ND (Atribución-NoComercial-SinDerivadas) para elementos de bioseguridad y CC BY-SA (Atribución-Compartirlgual) para demás productos, que establece su dominio público, pero no las transforma por defecto en creaciones huérfanas:

$\mathrm{BY}=\mathrm{El}$ crédito de autores permite localizar y redireccionar las críticas que sirvan para mejorar el diseño.

$\mathrm{NC}=$ Se exige plenamente la No comercialización, para fomentar su llegada a quienes lo requieren verdaderamente y evitar el abuso comercial contra el personal sanitario. El objetivo es fomentar las donaciones.

$\mathrm{ND}=$ Las modificaciones no son permitidas, en aquellos productos donde la revisión normativa generó la morfología resultante y ésta es determinante en la bio- 
protección del individuo. Si pueden ser reversionados todos aquellos productos que no interfieran con la bioseguridad.

SA = libre de compartir, remix (modificar) y reproducir, siendo aclaradas las modificaciones bajo la misma licencia.

Los productos están cargados en las webs de las entidades y agrupaciones participantes, el compromiso de la NO comercialización de estos es fundamental, al igual que la gestión interna de los centros de salud y laboratorios, acorde a los criterios establecidos por el Ministerio de Salud de la Nación, donde se privilegia el acceso a los productos según la escala de riesgo y el nivel de emergencia (producto de los brotes).

Debe remarcarse, desde Creative Commons, al crear el portal de licencias Open Covid Pledge, la implicancia que la liberación de la propiedad intelectual tiene como impacto directo en la mitigación de la Pandemia COVID-19, adherimos desde el CTA a la causa, aquello que nos moviliza es el rápido desarrollo, avance y diseminación de la tecnología necesaria para terminar con la proliferación de la enfermedad.

\section{Financiamiento}

- Pantallas faciales de ventilación indirecta para personal sanitario: Gestionado por el grupo de autoconvocados "Makers La Plata", con el aporte de los impresores reclutados y tandas de materiales (filamento y acetatos o similares) dos tandas iniciales aportadas por la Universidad Nacional de La Plata, aportes mixtos por 
empresas de filamentos y donaciones de particulares y restantes tandas completas financiadas desde el Centro Tecnológico Aeroespacial (con la gestión de fundación Facultad de Ingeniería).

- Pantallas faciales de ventilación directa 1 (para trabajadores esenciales/no sanitarios): Gestionadas por los filamentos obtenidos desde la configuración de aportes del modelo mencionado previamente, y las láminas transparentes gestionadas integralmente por el CTA.

- Pantallas faciales de ventilación directa 2 (para trabajadores esenciales/no sanitarios): Estas pantallas fueron las dos últimas series de producciones derivadas del modelo de ventilación directa 1, gestionadas en casi su totalidad por aportes desde el CTA a través de Fundación Facultad de Ingeniería.

Los siguientes tres productos gestionados integralmente desde el CTA:

- Sujetadores de barbijos/ ajustadores de talles.

- Gradillas.

- Gradillas ISO freezer/ Gradillas refrigeradas.

\section{Agradecimientos}

A los integrantes de la Comunidad MakerLP que aunaron sus esfuerzos junto a la EALP, en conjunto con el SLAD.

A la Fundación Facultad de Ingeniería por su inmediatez y transparencia de gestión. 
Innovación y Desarrollo Tecnológico y Social (2020) 2 (2): 83-117- Número especial COVID-19

A los municipios, Tapalqué (Intendente Gustavo Cocconi), Saladillo (personal médico del CAPS San Roque y Consultorios Médicos Sabbioni-López-Otros Asoc.) que confían en nuestro aporte.

Al laboratorio VacSal IBBM Conicet, por generar una construcción sinérgica ante el diseño.

\section{Referencias bibliográficas}

Dreyfuss, H. (1959). The measure of man. Human factors in design.

SICNOVA (2020). Pantallas faciales de código abierto provistas por SICNOVA para promover los desarrollos colaborativos internacionales de aplicación local. https://portal3dcovid19.es/productos/

Sociedad Argentina de Infectología (2020). Recomendaciones inter-institucional para la prevención de COVID-19 SADI / SATI / ADECI / INE https://www.sadi.org.ar/novedades/item/954-recomendaciones-inter-institucionalpara-la-prevencion-de-covid-19-sadi-sati-adeci-ine 